\title{
LA COOPERACIÓN CONTRA EL FRAUDE ADUANERO EN LA UNIÓN EUROPEA
}

\section{COOPERATION AGAINST CUSTOMS FRAUD IN THE EUROPEAN UNION}

\author{
David García Guerrero \\ Contratado FPU de Derecho Financiero y Tributario \\ Universidad de Jaén
}

Recibido: 14.06.2020 / Aceptado: 01.07.2020

DOI: https://doi.org/10.20318/cdt.2020.5615

\begin{abstract}
Resumen: El fraude aduanero ha constituido y constituye un elemento de preocupación para la Unión Europea porque conlleva una merma en los ingresos de la Hacienda comunitaria, repercutiéndole, en consecuencia, negativamente en su capacidad de gasto, dado que el apartado 1 del artículo 310 del Tratado de Funcionamiento de la Unión Europea establece que debe existir un equilibrio entre ingresos y gastos. Es por ello que la Unión profundiza continuamente en mecanismos para combatir el fraude aduanero, bien manteniendo aquellos que han funcionado, bien creando otros nuevos.
\end{abstract}

Palabras clave: cooperación, fraude aduanero, Unión Europea.

Abstract: Customs fraud constitutes a concern for the European Union because it leads to a decrease in community revenue, thereby having a negative impact on its expenditure capacity, since Paragraph 1 of Article 310 of the Treaty on the Functioning of the European Union (TFEU) states that there must be a balance between income and expenditure. It is for this reason that the European Union is continuously developing mechanisms to combat customs fraud, either by keeping those that have worked or by creating new ones.

Keywords: cooperation, Customs Fraud, European Union.

Sumario: I. Consideraciones preliminares: el fraude aduanero y la protección de los intereses financieros de la Unión. II. Las manifestaciones de asistencia mutua entre las Administraciones aduaneras de la Unión Europea y de cooperación entre los Estados miembros y la Comisión a la luz del Reglamento 515/97 y del Convenio Nápoles II. III. El Sistema de Información Aduanero (SIA) y el Fichero de Identificación de los Expedientes de Investigación Aduanera (FIDE). IV. La asistencia mutua entre Administraciones aduaneras de la Unión Europea para el cobro de créditos aduaneros. V. Los programas Hércules III y Aduana 2020. VI. La necesaria cooperación en materia de infracciones y sanciones aduaneras. VII. Conclusiones.

\section{Consideraciones preliminares: el fraude aduanero y la protección de los intereses financieros de la Unión}

1. El fraude es un fenómeno importante a nivel de la Unión Europea que se trata de combatir desde su mismo Derecho originario porque afecta a los intereses financieros de aquélla. Esto último constituye el fundamento de la lucha contra el fraude, tanto de la Unión Europea como de los Estados 
miembros, tal y como se refleja en el art. 325 del Tratado de Funcionamiento de la Unión Europea -en adelante, TFUE- ${ }^{1}$, que establece que no sólo las instituciones comunitarias ${ }^{2}$ deberán actuar en pro de la prevención y la lucha contra el fraude, como el Parlamento Europeo y el Consejo, sino también los Estados miembros como si de sus propios intereses se tratasen, bien individualmente, bien mediante acciones coordinadas con la Comisión ${ }^{3}$.

2. La primera cuestión que se debería abordar sería qué se entiende por fraude. El Reglamento (CE, Euratom) n ${ }^{\circ}$ 2988/95 del Consejo, de 18 de diciembre de 1995, relativo a la protección de los intereses financieros de las Comunidades Europeas hace referencia a "comportamientos que constituyen irregularidades" y "comportamiento irregular", como sinónimos, tal y como se destaca en los considerandos quinto y sexto, respectivamente. Pues bien, se dice en el sexto considerando que por "comportamiento irregular" también se ha de entender el "comportamiento de fraude" atendiendo a la definición del ya derogado Convenio relativo a la protección de los intereses financieros de las Comunidades Europeas ${ }^{4}$, sustituido por la Directiva (UE) 2017/1371 del Parlamento Europeo y del Consejo, de 5 de julio de 2017, sobre la lucha contra el fraude que afecta a los intereses financieros de la Unión a través del Derecho penal ${ }^{5}$.

3. Antes de abordar esta Directiva, para el Reglamento (CE, Euratom) $n^{\circ} 2988 / 95$, el que estábamos tratando, una irregularidad es toda acción u omisión que viole el Derecho de la Unión Europea por parte de un agente económico que afecte o pudiese afectar al presupuesto de ésta, bien mediante una disminución de ingresos, bien mediante un gasto indebido ${ }^{6}$.

4. Por su parte, el concepto de fraude ha sido definido en el art. 3 de la Directiva (UE) 2017/1371, a efectos de la misma ${ }^{7}$. En primer lugar, se requiere a los destinatarios de este texto legal que sean cons-

\footnotetext{
${ }^{1}$ Versiones consolidadas del Tratado de la Unión Europea y del Tratado de Funcionamiento de la Unión Europea, DOUE C 326 de 26 de noviembre de 2012, p. 47.

2 Somos plenamente conscientes de que el término "comunitario" deriva de Derecho comunitario, que era como anteriormente se conocía al Derecho de la Unión Europea en época de las Comunidades. Se utilizarán indistintamente en este trabajo estos conceptos por la raigambre que ha tenido en la doctrina española y también para no ser reiterativos.

${ }^{3}$ Cuando la misma norma de la Unión Europea habla de que los Estados miembros han de actuar como si de sus propios intereses se trataran, hemos de señalar que somos de la opinión de que se trata, efectivamente, de los mismos intereses porque la Unión Europea es una organización internacional de integración. Ahora bien, entra el juego el concepto de soberanía, pudiendo profundizar en obras como C. M. LóPEz EsPADAFor, "Las normas generales del Derecho Internacional ante el objetivo de combatir la evasión fiscal", Cuadernos de Derecho Transnacional, vol. 8, n 2, 2016, pp. 262 y ss. Desde una perspectiva más global, vid. C. M. LóPez EsPADAfor, "Recorrido transnacional de la soberanía tributaria", Cuadernos de Derecho Transnacional, vol. 10, $\mathrm{n}^{\mathrm{o}} 1,2018$, pp. 320 y ss. En relación con las tendencias que se están abriendo en este campo, vid. C. M. LÓPEZ ESPADAFOR, "Trends and sources of international taxation", Cuadernos de Derecho Transnacional, vol. 11, $\mathrm{n}^{\circ}$ 1, 2019 , pp. 447 y ss.

${ }^{4}$ Acto del Consejo, de 26 de julio de 1995, por el que se establece el Convenio relativo a la protección de los intereses financieros de las Comunidades Europeas, DOCE C 316 de 27 de noviembre de 1995, p. 48.

${ }^{5}$ El considerando 3 de la Directiva (UE) 2017/1371 del Parlamento Europeo y del Consejo, de 5 de julio de 2017, sobre la lucha contra el fraude que afecta a los intereses financieros de la Unión a través del Derecho penal, DOUE L 198 de 28 de julio de 2017, p. 29, recuerda que la protección de los intereses financieros de la Unión Europea ya se había tratado de armonizar mediante el Reglamento (CE, Euratom) n ${ }^{\circ}$ 2988/9 del Consejo, de 18 de diciembre de 1995, relativo a la protección de los intereses financieros de las Comunidades Europeas, DOCE L 312 de 23 de diciembre de 1995, p. 1, pero que es necesario profundizar todavía en la armonización de los Ordenamientos jurídicos de los Estados miembros en esta materia.

${ }^{6}$ M. FABIO, Manuale di diritto e pratica doganale, IV ed., Wolters Kluwer, Milán, 2017, pp. 758-759.

${ }^{7}$ Hasta el 6 de julio de 2019, se tomaba como referencia el concepto de fraude recogido en el Acto del Consejo, de 26 de julio de 1995, por el que se establece el Convenio relativo a la protección de los intereses financieros de las Comunidades Europeas. La entrada en vigor de la apenas mencionada Directiva (UE) 2017/1371 del Parlamento Europeo y del Consejo, de 5 de julio de 2017, sobre la lucha contra el fraude que afecta a los intereses financieros de la Unión a través del Derecho penal, y, por tanto, su aplicación, y, en particular, su art. 16, trajo consigo la sustitución del anterior Convenio de 1995 por la citada Directiva de 2017 desde la fecha que se indicaba al inicio para los Estados miembros que se encuentren vinculados por esta última.

Se considera relevante aclarar lo que en una primera aproximación asemeja una complicación del contenido del concepto de fraude: el Reglamento (UE, Euratom) no 883/2013 del Parlamento Europeo y del Consejo, de 11 de septiembre de
} 
titutivos de infracción pena $1^{8}$ los fraudes realizados intencionadamente, debiendo abarcar esta última la totalidad de los elementos del tipo ${ }^{9}$. Además, el fraude, que será una acción u omisión, ha de afectar a los intereses financieros de la Unión, lo cual se producirá en una serie de supuestos tasados en la misma Directiva: gastos no relacionados con los contratos públicos, gastos relacionados con los contratos públicos, ingresos distintos de los procedentes de los recursos propios del IVA e ingresos procedentes de los recursos propios del IVA ${ }^{10}$.

5. Ahora bien, dado la amplitud del tema, centrándonos en el fraude aduanero, éste se podría circunscribir en el apartado de ingresos distintos de los procedentes de los recursos propios del IVA, dado que los derechos de aduanas son impuestos cuya titularidad recae en la Unión Europea y que proporcionan, efectivamente, a esta última un ingreso. En cuanto al contenido de la infracción, se establece que deberá tipificarse como tal cualquier acción u omisión relativa a: a) el uso o presentación de declaraciones o documentos falsos, inexactos o incompletos; b) el incumplimiento de una obligación expresa de informar; o c) el uso indebido de un beneficio que se haya obtenido por cauces legales. Además, ha de tener una consecuencia, que no es otra que la disminución contraria a Derecho de los recursos del presupuesto comunitario o de presupuestos administrados por la Unión Europea o en su nombre.

6. Por tanto, infracción y fraude son definidos por el Ordenamiento comunitario de forma similar, si bien la Directiva (UE) 2017/1371 llega a ser más específica en el concepto de fraude. Debemos recordar que uno de los objetos de esta Directiva es sentar unas bases mínimas que delimiten el contorno de la infracción penal de fraude con la finalidad de conseguir una armonización de los Ordenamientos jurídicos de los Estados miembros.

7. Aún así, parece que el concepto de fraude aduanero sigue siendo abstracto, aunque nos vamos aproximando a una definición más nítida. Pues bien, teniendo en cuenta informes y demás documentación tanto de la Unión Europea como de la Agencia Estatal de Administración Tributaria española -en adelante, AEAT-, así como legislación ${ }^{11}$, podemos definir el fraude aduanero como la reducción o elusión del pago de los derechos aduaneros por medios ilegales, tales como la infravaloración de la mercancía, la declaración de un país de origen falso o la aplicación de una clasificación

2013, relativo a las investigaciones efectuadas por la Oficina Europea de Lucha contra el Fraude (OLAF) y por el que se deroga el Reglamento (CE) n ${ }^{\circ}$ 1073/1999 del Parlamento Europeo y del Consejo y el Reglamento (Euratom) $n^{\circ} 1074 / 1999$ del Consejo, DOUE L 248 de 18 de septiembre de 2013, p. 6, la recoge en la definición 3 del art. 2 de este texto normativo, estableciéndose que se habrá de atender al sentido que se le otorgue a tal término en cada acto de la Unión Europea que trate sobre el mismo. Ahora bien, no aparece solamente el fraude, sino que también se habla de corrupción o cualquier otra actividad ilegal que vaya en detrimento de los intereses financieros de la Unión. Es por ello que se remite al acto del Derecho de la Unión Europea en particular que los trate. El legislador comunitario podría haber dotado de mayor seguridad jurídica a tales conceptos, ofreciendo incluso una definición mediante referencias normativas por separado, pero, como puede apreciarse, no ha sido tal el caso.

${ }^{8}$ Los destinatarios son los Estados miembros, pero no todos. En particular, se hace referencia expresa a tres Estados miembros: Irlanda, Reino Unido y Dinamarca. Mientras Irlanda se compromete a adoptar y aplicar la Directiva, Reino Unido y Dinamarca mostraron su voluntad de no participar, según se refleja en los considerandos 36, 37 y 38 .

${ }^{9}$ Art. 3.1 y considerando 11 de la Directiva (UE) 2017/1371.

${ }^{10}$ Art. 3.2 de la Directiva (UE) 2017/1371.

${ }^{11}$ No encontramos una definición exacta en el Derecho de la Unión Europea o en el Derecho nacional de fraude aduanero, pero sí encontramos numerosas referencias a tal concepto. Así, el Reglamento (UE) 2015/1525 del Parlamento Europeo y del Consejo, de 9 de septiembre de 2015, por el que se modifica el Reglamento (CE) n 515/97 del Consejo relativo a la asistencia mutua entre las autoridades administrativas de los Estados miembros y a la colaboración entre estas y la Comisión con objeto de asegurar la correcta aplicación de las reglamentaciones aduanera y agraria, DOUE L 243 de 18 de septiembre de 2015, p. 1 , hace referencia en numerosas ocasiones al fraude y, también, más concretamente, al fraude en materia aduanera o al fraude aduanero, como en los considerandos 4, 5, 6, 7, 15 y 16. El mismo considerando 4 relaciona los conceptos de fraude en el tráfico aduanero de la Unión Europea y de infracción de la reglamentación aduanera. 
arancelaria de productos que tengan un gravamen inferior al que le correspondería ${ }^{12}$, incumpliendo, así, la normativa aduanera ${ }^{13}$.

8. Una vez aportada la definición de fraude aduanero, convendría diferenciarlo del fraude fiscal. Esta cuestión nace porque la misma AEAT los distingue ${ }^{14} \mathrm{y}$, en definitiva, el fraude aduanero se trata de la reducción o eliminación de la carga tributaria que recae sobre una mercancía, de un impuesto aduanero y, por ende, del ámbito fiscal.

9. Pues bien, ante ello, siendo puristas en el análisis de la cuestión que planteamos, preferimos distinguir, inicialmente, entre fraude fiscal y fraude que afecta a los intereses financieros de la Unión Europea: así, la diferencia recaería en el sujeto activo del tributo en cuestión, estando en presencia de fraude fiscal cuando se trate de un tributo cuya titularidad corresponde a la Hacienda Pública estatal, autonómica, foral o local ${ }^{15}$; y estando en presencia de fraude que afecta a los intereses financieros de la Unión Europea cuando se trate de una minoración de los ingresos de la Hacienda comunitaria. Dicho lo cual, dentro de este último tipo de fraude, es decir, el que afecta a las arcas de la Unión Europea, encontraremos el fraude aduanero, ya que se encuadra en el ámbito de ingresos distintos de los procedentes del IVA.

10. Esta visión ha cristalizado en ámbito penal, en los arts. 305, 305 bis y 306 del Código Penal: si se trata de una defraudación de un tributo estatal, como, por ejemplo, del Impuesto sobre la Renta de las Personas Físicas, se podría subsumir en el apartado 1 del art. 305, ya que se especifica que se persigue la conducta de eludir el pago de tributos, entre otras, de la Hacienda Pública estatal -además de la autonómica, foral y local-; si se trata, por el contrario, de la defraudación de un tributo de la Unión Europea, como son los derechos de aduanas, se subsumiría en el apartado 3 del mismo artículo, puesto que se habla de que el ilícito consistiría en las conductas del apartado 1, pero cuando se vea afectada la Hacienda de la Unión Europea, refiriéndose, por tanto, a tributos comunitarios ${ }^{16}$.

11. Desempeña un papel fundamental la Oficia Europea de Lucha contra el Fraude -en adelante, OLAF, por sus siglas en inglés-, que vino a sustituir el Grupo operativo de coordinación de la lucha contra el fraude, que, a su vez, fue la sucesora de la Unidad de coordinación de la lucha contra el fraude ${ }^{17}$. Una de las funciones fundamentales que ostenta esta Oficina es, entre otras, la lucha contra el fraude.

${ }^{12}$ Informe especial. Regímenes de importación: las insuficiencias en el marco jurídico y una aplicación ineficaz afectan a los intereses financieros de la UE, Tribunal de Cuentas Europeo, $\mathrm{n}^{\circ}$ 19, 2017, p. 11. Vd. también Resolución de 11 de enero de 2019, de la Dirección General de la Agencia Estatal de Administración Tributaria, por la que se aprueban las directrices generales del Plan Anual de Control Tributario y Aduanero de 2019, AEAT, 2019, pp. 3476-3477: en el apartado que habla de la prevención y control del fraude aduanero, se refleja que se han de realizar toda una serie de actuaciones de comprobación con el fin de establecer si la cuantía pagada en concepto de derechos de aduanas es la que corresponde, luchando, así, contra las posibles irregularidades que reduzcan o eliminen la tributación de la mercancía que se importa a la Unión Europea.

${ }^{13}$ Con "normativa aduanera" hacemos referencia no sólo al Derecho de la Unión Europea en materia aduanera, sino también al nacional, como así se entiende también en el Reglamento (UE) nº 952/2013 del Parlamento Europeo y del Consejo, de 9 de octubre de 2013, por el que se establece el código aduanero de la Unión (refundición), DOUE L 269 de 10 de octubre de 2013, p. 12, en su definición 2 del art. 5.

${ }^{14}$ La Resolución de 21 de enero de 2020, de la Dirección General de la Agencia Estatal de Administración Tributaria, por la que se aprueban las directrices generales del Plan Anual de Control Tributario y Aduanero de 2020, AEAT, 2020, distingue continuamente entre "fraude tributario y aduanero". De hecho, en el mismo título de esta norma se habla de "control tributario y aduanero".

${ }^{15}$ Distinción que realiza el Derecho español. En tal sentido, vid. art. 305.1 de la Ley Orgánica 10/1995, de 23 de noviembre, del Código Penal, BOE de 24 de mayo de 1995.

16 J. Martín Queralt, C. Lozano Serrano, J. M. Tejerizo López y G. Casado Ollero, Curso de Derecho Financiero y Tributario, $28^{\mathrm{a}}$ ed., Tecnos, Madrid, 2017, pp. 691-695: así, si se tratase de un ingreso que no tuviese naturaleza tributaria, se subsumiría tal conducta en el art. 306 del Código Penal. Por tanto, el fraude que afecta a los intereses financieros de la Unión Europea englobaría tanto al fraude aduanero -que podría englobarse en el art. 305.3, cuando se den todos los elementos del tipo, naturalmente- como a otros tipos de fraude, piénsese al fraude relacionado con la percepción de fondos o ayudas europeas -subsumiéndose en el art. 306-.

${ }^{17}$ Considerando 3 de la Decisión de la Comisión, de 28 de abril de 1999, por la que se crea la Oficina Europea de Lucha contra el Fraude (1999/352/CE, CECA, Euratom), DOCE L 136 de 31 de mayo de 1999, p. 1. 
A tal fin, será el cauce entre la Comisión y los Estados miembros en materia de ayuda de la primera a estos últimos a la cooperación, proveerá actividades, como intercambio de buenas prácticas o prestar asistencia técnica, por ejemplo, preparará los textos normativos de la Comisión que tengan como objeto la lucha contra el fraude, ejercerá de interlocutor directo con las autoridades pertinentes -policía y tribunales- y de representación de los servicios de la Comisión en el foro que corresponda. Como es natural, para que una institución pueda luchar de forma eficiente contra el fraude -además de la corrupción y demás actividades ilegales que vayan en contra de los intereses financieros de la Unión Europea- se requiere que pueda ejercer sus funciones con independencia, de ahí que se dé tal nota tanto en el director de la Oficina como en el Comité de vigilancia ${ }^{18}$.

12. Dada la gran envergadura del fenómeno del fraude aduanero, centraremos la atención en la cooperación en la lucha contra el fraude aduanero en la Unión, que se plasma en los ámbitos de actuación que se desarrollarán posteriormente, siendo aquellos que hemos retenido más interesantes desde el punto de vista de este trabajo por no haber profundizado en demasía la doctrina en su estudio.

13. En particular, en el presente trabajo abordaremos la cooperación contra el fraude aduanero en la Unión Europea mediante su positivización en normas comunitarias que obligan a los Estados miembros a colaborar atendiendo al ámbito específico de estas normas. Incluso nos podríamos plantear la posible existencia de un deber general de colaboración entre Estados en ámbito tributario a la luz del Derecho Internacional General ante la problemática del fraude fiscal -que es perfectamente extrapolable también al fraude aduanero, dado que, en definitiva, en ambos casos se trata de una minoración de la cuantía a pagar por un tributo o de ni siquiera abonarlo-, cuestión que ha sido abordada por la doctrina, pero que no es pacífica. Como bien señala LóPEz ESPADAFOR, no podemos afirmar que haya tal deber fundado en un principio de Derecho Internacional General o en una costumbre internacional, pues, entonces, carecería de sentido y, por ende, de utilidad, la firma de convenios entre Estados u otros textos de carácter internacional, pero también se podría defender que la plasmación de ese principio en un convenio o texto internacional se realizase con la finalidad de otorgar seguridad jurídica en la materia ${ }^{19}$.

\section{Las manifestaciones de asistencia mutua entre las Administraciones aduaneras de la Unión Eu- ropea y de cooperación entre los Estados miembros y la Comisión a la luz del Reglamento 515/97 y del Convenio Nápoles II}

14. La cooperación con fines aduaneros se rige por dos textos legales básicos ${ }^{20}$ : de un lado, el Reglamento (CE) $n^{\circ}$ 515/97 relativo a la asistencia mutua entre las autoridades administrativas de los Estados miembros y a la colaboración entre estas y la Comisión con objeto de asegurar la correcta aplicación de las reglamentaciones aduanera y agraria -en adelante, Reglamento 515/97-21; y, de otro lado, el Convenio celebrado sobre la base del artículo K.3 del Tratado de la Unión Europea, relativo a la asistencia mutua y la cooperación entre las administraciones aduaneras -en adelante, Convenio Nápoles II-22.

\footnotetext{
${ }^{18}$ Considerando 5 y arts. 2 a 4 de la Decisión de la Comisión, de 28 de abril de 1999, por la que se crea la Oficina Europea de Lucha contra el Fraude (1999/352/CE, CECA, Euratom).

19 Sobre este asunto, vid. C. M. López Espadafor, "Alcance del deber general de colaboración entre Estados en la lucha contra el fraude fiscal”, Revista Española de Derecho Financiero, nº 173, 2017, p. 17. Para un estudio más específico donde se estudia si existe un principio de Derecho Internacional General que contenga el deber de colaboración entre Estados, vid. C. M. LÓPEZ ESPADAFOR, "Globalización en el deber de cooperación entre administraciones tributarias ante la persistencia de los paraísos fiscales", Quincena Fiscal, nº 8, 2017, p. 19.

${ }^{20}$ F. VISMara: Corso di diritto doganale. Diritto dell'Unione europea e diritto interno, G. Giappichelli Editore, Turín, 2018, pp. 79-80.

${ }^{21}$ Reglamento (CE) no 515/97 relativo a la asistencia mutua entre las autoridades administrativas de los Estados miembros y a la colaboración entre estas y la Comisión con objeto de asegurar la correcta aplicación de las reglamentaciones aduanera y agraria, DOCE L 82 de 22 de marzo de 1997, p. 1.

${ }^{22}$ Convenio celebrado sobre la base del artículo K.3 del Tratado de la Unión Europea, relativo a la asistencia mutua y la
} 
15. Antes de adentrarnos en concreto en los instrumentos jurídicos de asistencia mutua entre las Administraciones aduaneras de la Unión Europea y de cooperación entre los Estados miembros y la Comisión, se ha de tratar de diferenciar el ámbito de aplicación del Reglamento 515/97 y del Convenio Nápoles II.

16. Si atendemos al art. 1.1 del Reglamento 515/97, el objeto del mismo sería regular la forma de colaboración entre las Administraciones aduaneras de los Estados miembros entre sí y entre éstas y la Comisión con la finalidad de garantizar que se respeten las reglamentaciones comunitarias aduanera y agraria. Por su parte, el art. 1.1 del Convenio Nápoles II afirma que tal cooperación se realizará tanto para la prevención e investigación de las infracciones de las disposiciones aduaneras nacionales, así como para la persecución y represión de las infracciones de las disposiciones aduaneras nacionales y comunitarias.

17. Expuestos estos dos artículos, que contendrían el ámbito de aplicación de cada norma, no parece que se aclare completamente la cuestión. Así, convendría acudir a los considerandos de ambas normas. Comenzando por el Reglamento 515/97, su segundo considerando afirma que se busca con este texto jurídico la prevención y la indagación de las infracciones a las reglamentaciones comunitarias aduanera y agraria y su quinto considerando establece que este Reglamento comunitario no impide la aplicación del "Convenio de 1967 de asistencia mutua entre las administraciones aduaneras en aquellas materias que continúan siendo competencia exclusiva de los Estados miembros", que era el Convenio Nápoles, el precedente del Convenio Nápoles II.

18. Llegados a este punto, se ha de traer a colación el Informe explicativo sobre el Convenio celebrado sobre la base del artículo K.3 del Tratado de la Unión Europea relativo a la asistencia mutua y la cooperación entre las administraciones aduaneras ${ }^{23}$, esto es, el Informe explicativo sobre el Convenio Nápoles II. En el párrafo 1.2 se resuelve esta duda del ámbito de aplicación del Reglamento 515/97 y del Convenio Nápoles II de forma clara: establece que el Reglamento 515/97 contempla la prevención e investigación de la normativa aduanera comunitaria.

19. Por tanto, si bien el art. 1.1 del Convenio Nápoles II establecía como finalidades tanto la prevención, investigación, persecución y represión de las infracciones contra las normativas aduaneras nacionales, como la persecución y represión de las infracciones contra la normativa aduanera comunitaria, se nos aclara en ese párrafo 1.2 del Informe explicativo sobre el Convenio Nápoles II que la prevención e investigación de las infracciones contra la normativa aduanera comunitaria será una finalidad del Reglamento 515/97.

20. Sin lugar a dudas, en vez de la existencia de este Informe explicativo, o del precepto que aclara el ámbito de aplicación del Reglamento 515/97 y el del Convenio Nápoles II, hubiese sido preferible una reforma del art. 1 del Reglamento 515/97 para incluirlo expresamente, incluso una referencia expresa tanto en éste como en el Convenio Nápoles II una referencia al otro, dada su relación de complementariedad en pro de la cooperación en contra de las infracciones a la normativa aduanera, ya sea ésta nacional o de ámbito de la Unión Europea.

21. Así las cosas, antes de entrar a analizar las manifestaciones de asistencia mutua y colaboración, se ha de destacar que existe una similitud, en parte, entre las reflejadas en el Reglamento $515 / 97$ y las del Convenio Nápoles II $^{24}$. Por este motivo era menester diferenciar en qué campos rigen

cooperación entre las administraciones aduaneras, DOCE C 24 de 23 de enero de 1998, p. 2.

${ }^{23}$ Informe explicativo sobre el Convenio celebrado sobre la base del artículo K.3 del Tratado de la Unión Europea relativo a la asistencia mutua y la cooperación entre las administraciones aduaneras, DOCE C 189 de 17 de junio de 1998 , p. 1.

${ }^{24}$ El Anexo A del Informe explicativo sobre el Convenio celebrado sobre la base del artículo K.3 del Tratado de la Unión Europea relativo a la asistencia mutua y la cooperación entre las administraciones aduaneras trata de poner de manifiesto, 
ambas normas.

22. Vamos a diferenciar tres grupos en función de los sujetos implicados: si se da entre Estados miembros, existe la asistencia previa petición, la asistencia esporádica y las formas especiales de cooperación; también se darán relaciones entre los Estados miembros y la Comisión; y, por último, relaciones entre los Estados miembros y países terceros.

23. Comenzando por el primer grupo, es decir, las relaciones entre los Estados miembros, la asistencia previa petición y la asistencia espontánea se prevén en los Títulos I y II del Reglamento 515/97 y en los Títulos II y III del Convenio Nápoles II, mientras que las formas especiales de cooperación se recogen solamente en el Título IV del Convenio Nápoles II.

24. En cuanto a la asistencia previa solicitud, un principio fundamental que la guía es la actuación por parte de la autoridad requerida como si actuase por cuenta propia o a instancias de otra entidad de su Estado ${ }^{25}$. Además, por un lado, el Reglamento 515/97 añade que la autoridad requerida habrá de ofrecer toda la información requerida con el objeto de asegurar la observancia de las disposiciones previstas por las reglamentaciones aduanera y agraria en relación a las personas que han debido presentar una declaración en aduana (razón social, dirección de la sociedad, nombre de los dirigentes o nombre de los directores, entre otras $)^{26}$; y, por otro lado, el Convenio Nápoles II recuerda que la autoridad requerida habrá de ofrecer toda información respecto a la infracción objeto de investigación por parte de la autoridad requirente, sin necesidad de que esta última haya de realizar, adicionalmente, una solicitud complementaria ${ }^{27}$.

25. Pasando al contenido de esta solicitud, lo regula el art. 9 del Convenio Nápoles II, pero no hay ningún precepto equivalente en el Reglamento 515/9728. Pues bien, respecto al contenido de la solicitud del Convenio Nápoles II, ésta estará constituida por la siguiente información: se habrá de identificar la autoridad requirente; qué medida, de las que se verán a continuación, se requiere; objeto y medida; fundamentación jurídica oportuna; datos de las personas físicas o jurídicas objeto de la investigación y, normalmente, resumen de los hechos.

26. Cuando se decía supra "manifestaciones de asistencia mutua", se hacía referencia a las medidas que se prevén de asistencia mutua entre los Estados. Pues bien, en referencia a las medidas que se establecen previa solicitud, éstas son cuatro: solicitudes de información ${ }^{29}$, solicitudes de vigilancia sobre personas, mercancías, lugares o medios de transporte ${ }^{30}$, solicitudes de investigaciones sobre operaciones $^{31}$ y notificaciones al destinatario ${ }^{32}$.

27. En cuanto a la asistencia espontánea, podría definirse, en contraposición con la anterior, como aquélla que se realiza sin necesidad de que la autoridad requirente envíe una solicitud a la autoridad requerida ${ }^{33}$.

28. Existen dos medidas de asistencia espontánea: la vigilancia -remitiéndose ambos cuerpos

\footnotetext{
mediante una tabla comparativa, las similitudes entre las manifestaciones del Reglamento 515/97 y el Convenio Nápoles II.

${ }^{25}$ Art. 4.1 del Reglamento 515/97 y art. 8.1 del Convenio Nápoles II.

${ }^{26}$ F. Vismara, ob. cit., pp. 81-82.

${ }^{27}$ Art. 8.2 del Convenio Nápoles II.

${ }^{28}$ Informe explicativo del Convenio Nápoles II, Anexo A, p. 15.

${ }^{29}$ Arts. 5, 8 y 10 del Reglamento 515/97 y art. 10 del Convenio Nápoles II.

${ }^{30}$ Art. 7 del Reglamento 515/97 y art. 11 del Convenio Nápoles II.

${ }^{31}$ Art. 9 del Reglamento 515/97 y art. 12 del Convenio Nápoles II.

${ }^{32}$ Art. 6 del Reglamento 515/97 y art. 13 del Convenio Nápoles II.

${ }^{33}$ F. VISMARA, ob. cit., pp. 80-82.
} 
legislativos $^{34}$ a la configuración de este tipo de manifestación establecida para la asistencia previa solicitud- ${ }^{35}$ y la comunicación espontánea de información pertinente sobre infracciones ${ }^{36}$.

29. Dentro de este primer grupo de asistencia mutua entre Estados también se encuentran como medidas unas formas especiales de cooperación previstas solamente en el Título IV del Convenio Nápoles II. El Reglamento 515/97 no las prevé ${ }^{37}$. Estas formas especiales de cooperación se rigen por unos principios, debiendo destacar que, como regla general, se exige que se realice una solicitud previa para estas formas de la autoridad requirente a la autoridad requerida, remitiéndose al art. 9 del Convenio expuesto anteriormente. Ahora bien, también existen excepciones, admitiéndose que pueda realizarse de forma espontánea con unos requisitos especiales. Además, se permitirá solamente para determinadas infracciones, como tráfico ilícito de determinados bienes (drogas, armas, explosivos o materiales nucleares, entre otros), comercio transfronterizo ilegal de mercancías sometidas a gravamen que generen una merma importante en la Hacienda de la Unión Europea o cualquier otro comercio de mercancías prohibidas por la normativa aduanera de la Unión o nacionales ${ }^{38}$.

30. Se prevén cuatro formas especiales de cooperación: la persecución con cruce de frontera a una persona ${ }^{39}$-piénsese que podrán perseguir en otro Estado que sea parte de la Convención en el caso de que la persona haya sido hallada de forma flagrante en la comisión de las infracciones del art.19.2 de este Convenio y cuando no se haya podido avisar a las autoridades de ese Estado o cuando no hayan podido llegar a tiempo ${ }^{40}$-, la vigilancia transfronteriza a una persona ${ }^{41}$, las entregas vigiladas de mercancías $^{42}$, investigaciones encubiertas ${ }^{43}$-en las que se autoriza a funcionarios a operar con una identidad ficticia ${ }^{44}$ - y la creación de equipos comunes de investigación especia ${ }^{45}$.

31. En el segundo grupo habíamos decidido englobar las relaciones entre los Estados miembros y la Comisión. En este caso, solamente el Reglamento 515/97 en su Título III es el que las regula, no así el Convenio Nápoles II. La cuestión que se ha de resolver es el motivo por el que el Reglamento ha decidido otorgar a la Comisión un papel importante en esta materia. Pues bien, habríamos de partir de la base de que, como recuerda el primer considerando de este Reglamento, la Comisión tiene encomendada la función de vigilar la correcta aplicación tanto del Derecho originario de la Unión como del Derecho derivado consecuencia del anterior, y este reglamento se fundamenta en el entonces vigente Tratado constitutivo de la Comunidad Europea. En ese sentido, se dice que es la "guardiana" de los Tratados ${ }^{46}$.

32. Para garantizar una correcta aplicación de la normativa comunitaria aduanera y agraria, la relación que habrá de existir entre los Estados miembros y la Comisión tendrá diferentes manifestaciones: la comunicación de toda aquella información de que dispongan y que sea relevante al otro a efectos del Reglamento 515/97; la creación y gestión de distintas bases de datos ("base de datos de transporte" o la "base de datos de importación, exportación y tránsito" ${ }^{47}$ ); la formación y asistencia técnica por parte

\footnotetext{
34 Así, el art. 14 del Reglamento 515/97 remite al su art. 7 y el art. 16 del Convenio Nápoles II remite a su art. 11.

35 Art. 14 del Reglamento 515/97 y art. 16 del Convenio Nápoles II.

36 Art. 15 del Reglamento 515/97 y art. 17 del Convenio Nápoles II.

37 Muestra de ello es el Informe explicativo del Convenio Nápoles II, Anexo A, p. 16.

38 Art. 19 del Convenio Nápoles II.

39 Art. 20 del Convenio Nápoles II.

${ }^{40}$ F. Vismara, ob. cit., p. 80.

41 Art. 21 del Convenio Nápoles II.

42 Art. 22 del Convenio Nápoles II.

43 Art. 23 del Convenio Nápoles II.

${ }^{44}$ F. Vismara, ob. cit., p. 80.

45 Art. 24 del Convenio Nápoles II.

46 J. Alcaide Fernández y R. Casado Raigón, Curso de Derecho de la Unión Europea, 2a ed., Tecnos, Madrid, 2014, p. 122.

47 Ambas bases de datos fueron establecidas por el Reglamento (UE) 2015/1525 del Parlamento Europeo y del Consejo, de 9 de septiembre de 2015, por el que se modifica el Reglamento (CE) $\mathrm{n}^{\circ}$ 515/97 del Consejo relativo a la asistencia mutua entre las autoridades administrativas de los Estados miembros y a la colaboración entre estas y la Comisión con objeto de asegurar
} 
de la Comisión a responsables de enlaces con terceros países y entes internacionales y a los Estados miembros; o el requerimiento de la Comisión a las autoridades competentes de los Estados miembros de todo documento justificativo de declaraciones de importación y exportación relacionados con investigaciones sobre infracciones de la normativa aduanera ${ }^{48}$.

33. El tercer grupo está compuesto por las relaciones con terceros países. La finalidad no es otra que comprobar si un determinado actuar es contrario a la normativa aduanera y agraria y, en el caso de que así fuese, cuál es su amplitud o envergadura ${ }^{49}$. Las medidas previstas son la obtención de asistencia por parte de esos países terceros, siempre y cuando exista un compromiso jurídico previo, el establecimiento de misiones comunitarias de cooperación e investigación administrativa en estos países extracomunitarios y la facilitación de la información obtenida por los Estados miembros de terceros países en el contexto de la asistencia mutua cuando ello suponga un interés particular para el correcto funcionamiento de las normativas aduanera y agraria ${ }^{50}$.

\section{EI Sistema de Información Aduanero (SIA) y el Fichero de Identificación de los Expedientes de Investigación Aduanera (FIDE)}

34. Mediante el Título V del Reglamento $515 / 97^{51}$ se crea el Sistema de Información Aduanero, también denominado SIA, con el objeto de dar cumplimiento al mismo espíritu del Reglamento, que no es otro que la prevención, investigación y persecución de todo acto que sea contrario a las reglamentaciones aduanera y agraria a través de la disponibilidad de datos relevantes.

35. La razón de la exclusión del epígrafe anterior de este trabajo de este sistema de información para que constituya un apartado propio es, por un lado, la naturaleza de esta medida, la medida de creación del SIA, y, por otro lado, su importancia, la cual reside en la puesta en marcha de un sistema de información que sea útil, pues hemos de recordar que las Administraciones aduaneras no aplican solamente disposiciones de carácter comunitario, sino también nacionales, por lo que el SIA se convierte, así, en una oportunidad imprescindible en cuanto herramienta única para la aplicación de todas estas disposiciones ${ }^{52}$.

36. El SIA aglutina información relativa a las siguientes categorías ${ }^{53}$ : mercancías; medios de transporte; empresas; personas; tendencias del fraude; competencias disponibles; retenciones, embargos o confiscaciones de mercancías; y retenciones, embargos o confiscaciones de dinero en efectivo ${ }^{54}$.

37. Usan este banco central de datos las autoridades aduaneras de los Estados miembros, recayendo en la Comisión su gestión técnica. La elección de las autoridades que tienen acceso al contenido del SIA se realiza tras la intervención de los Estados miembros y de la Comisión: los Estados miembros proponen cuáles serán las autoridades que proponen, debiendo ser ratificadas, después, por la Comisión, y se publica en el Boletín Oficial de la Unión Europea ${ }^{55}$.

\footnotetext{
la correcta aplicación de las reglamentaciones aduanera y agraria.

48 Arts. 17 a 18 sixties del Reglamento 515/97.

49 C. M. López espadafor y D. García Guerrero, "La Administración aduanera", Documentos de Trabajo, Instituto de Estudios Fiscales, 2019, p. 47.

${ }^{50}$ Arts. 19 a 22 del Reglamento 515/97.

${ }^{51}$ En particular, su establecimiento se establece mediante el art. 23 del Reglamento 515/97.

${ }^{52}$ Considerando 13 del Reglamento 515/97.

${ }^{53}$ F. VismaRA, ob. cit., p. 82.

${ }^{54}$ La determinación de los elementos que se han de incluir en el SIA en referencia a las citadas categorías la realiza el art. 1 y el Anexo del Reglamento de Ejecución (UE) 2016/346 de la Comisión, de 10 de marzo de 2016, por el que se determinan los elementos que deben incluirse en el Sistema de información aduanera, DOUE L 65 de 11 de marzo de 2016, p. 40.

${ }_{55}$ Art. 29 del Reglamento 515/97.
} 
38. Teniendo en cuenta la naturaleza de los datos introducidos en el SIA, el Reglamento 515/97 fija tanto el procedimiento como las garantías oportunas en cuanto a su tratamiento (modificación, almacenamiento o seguridad, responsabilidad, publicación, o protección y control de los datos de tipo personal $)^{56}$.

39. Por otro lado, el Título V Bis del Reglamento 515/97 crea una base de datos específica dentro del SIA, que es el Fichero de identificación de los expedientes de investigaciones aduaneras, también denominado FIDE $^{57}$. Como se manifestaba respecto al SIA, su función es servir para prevenir toda conducta que pudiera ser contraria a las reglamentaciones aduanera y agraria en materia de entrada y salida de mercancías del territorio aduanero de la Unión; además, podrán acceder al FIDE las autoridades aduaneras, siendo la Comisión la encargada de su gestión técnica ${ }^{58}$.

40. Gracias al FIDE, se facilita la identificación de las autoridades que estén investigando o ya hayan investigado sobre las mismas personas físicas o jurídicas a la Comisión -en los expedientes de coordinación y las misiones comunitarias en países terceros-, o a las autoridades aduaneras de los Estados miembros que tengan acceso porque hayan sido elegidas atendiendo al art. 29 del Reglamento -en el caso de los expedientes de investigación o realicen una investigación a una o varias personas o empresas- ${ }^{59}$.

41. El funcionamiento y utilización del FIDE, así como la conservación de los datos en él incluidos, se rige por los Capítulos 2 y 3 del Título V Bis del Reglamento. De igual modo que expresábamos supra respecto al SIA, la naturaleza de los datos introducidos en el FIDE requiere de un tratamiento específico.

42. Se comenzaba la exposición del SIA subrayando su importancia. De igual modo, las últimas líneas que le dedicamos versarán sobre lo mismo. Piénsese que existen dos Decisiones de la Unión Europea que demuestran que la digitalización de la aduana es una apuesta firme comunitaria y que, bien empleada, supone una herramienta importante en la lucha contra el fraude aduanero.

43. Por una parte, la Decisión 2009/917/JAI del Consejo, de 30 de noviembre de 2009, sobre la utilización de la tecnología de la información a efectos aduaneros, cuya aprobación tuvo unas consecuencias importantes por facilitar la coordinación y cooperación en la lucha contra las infracciones a las disposiciones aduaneras comunitarias y nacionales, dado que permitió que tanto la Oficina Europea de Policía (Europol) y la Unidad de Cooperación Judicial (Eurojust) pudiesen acceder a las bases de datos del SIA, donde se incluye el FIDE ${ }^{60}$.

44. Por otra parte, la Decisión $n^{\circ} 70 / 2008 / \mathrm{CE}$ del Parlamento Europeo y del Consejo, de 15 de enero de 2008, relativa a un entorno sin soporte papel en las aduanas y el comercio, hace especial hincapié en que los sistemas aduaneros electrónicos son esenciales para que se produzca ese intercambio de información tan necesario, por lo que emplaza a la Comisión y a los Estados miembros a implantar estos sistemas electrónicos ${ }^{61}$.

\footnotetext{
${ }^{56}$ Capítulos 3 a 8 del Título V del Reglamento 515/97.

${ }^{57}$ F. Vismara, ob. cit., p. 82.

${ }_{58}$ Art. 41 bis. 5 del Reglamento 515/97.

${ }^{59}$ Art. 41 bis. 3 del Reglamento 515/97.

${ }^{60}$ Considerando 4 de la Decisión 2009/917/JAI del Consejo, de 30 de noviembre de 2009, sobre la utilización de la tecnología de la información a efectos aduaneros, DOUE L 323 de 10 de diciembre de 2009, p. 20.

${ }^{61}$ Arts. 1 y 2 de la Decisión n ${ }^{\circ}$ 70/2008/CE del Parlamento Europeo y del Consejo, de 15 de enero de 2008, relativa a un entorno sin soporte papel en las aduanas y el comercio, DOUE L 23 de 26 de enero de 2008, p. 21.
} 


\section{La asistencia mutua entre Administraciones aduaneras de la Unión Europea para el cobro de créditos aduaneros}

45. La regulación a nivel comunitario de asistencia en materia de cobros de créditos aduaneros se encuentra en la Directiva 2010/24/UE del Consejo, de 16 de marzo de 2010, sobre la asistencia mutua en materia de cobro de los créditos correspondientes a determinados impuestos, derechos y otras medidas $^{62}$. Ahora bien, como el nombre de esta Directiva indica y, posteriormente, pone de relieve su articu$l^{1 a d o}{ }^{63}$, no se hace referencia exclusivamente a los créditos aduaneros, sino también cualquier clase de tributo o derecho que recauden los Estados miembros, las devoluciones, intervenciones y otras medidas en relación al Fondo Europeo Agrícola de Garantía -FEAGA- y también al Fondo Europeo Agrícola de Desarrollo Rural -FEADER- o las exacciones y demás derechos previstos en la organización común de mercado del sector del azúcar, además de tasas, sanciones administrativas o multas que estén relacionados con los citados tributos o derechos ${ }^{64}$. Nosotros nos centraremos en los créditos aduaneros, dado que son los que afectan al fraude aduanero.

46. Esta asistencia mutua cristalizará en las siguientes actuaciones: intercambio de información, asistencia para la notificación de documentos, medidas de cobro y medidas cautelares.

47. Se establecen unos "modelos normalizados" para encauzar la petición de asistencia mutua, facilitando, en consecuencia, esa asistencia. La vía será electrónica, siempre y cuando se dispongan de los medios oportunos al efecto. Así, la no utilización del soporte electrónico no será un defecto que conlleve la invalidez de las actuaciones ${ }^{65}$.

48. En cuanto a las dos primeras actuaciones en que cristaliza la asistencia mutua en materia de cobro de créditos aduaneros, son manifestaciones previstas en el Reglamento 515/97 y en el Convenio Nápoles II, aunque tienen otros ámbitos de aplicación: mediante el intercambio de información, el Estado miembro acreedor obtiene toda información, generalmente patrimonial, que le sea útil para poder llevar a cabo el cobro al deudor. Puede ser también producirse sin solicitud previa. Además, se prevé la posibilidad de que estén presentes los funcionarios autorizados por la autoridad requirente ${ }^{66}$. Es importante destacar que el Estado requerido no puede invocar el secreto bancario como causa para no ejecutar el mandato del Estado requirente, que es un aspecto fundamenta ${ }^{67}$; por su parte, la asistencia para la notificación de documentos no tendrá que ser solamente con respecto al crédito, sino también con respecto a aquellos documentos que estén relacionados con éste ${ }^{68}$, teniendo un carácter subsidiario, dado que el Estado requirente deberá haber intentado realizar la notificación al deudor y no haberlo conseguirlo ${ }^{69}$.

${ }^{62}$ En particular, los derechos de aduanas se encuadrarían en el art. 2.1 a) de la Directiva 2010/24/UE del Consejo, de 16 de marzo de 2010, sobre la asistencia mutua en materia de cobro de los créditos correspondientes a determinados impuestos, derechos y otras medidas, DOUE L 84 de 31 de marzo de 2010, p. 1, dado que son recaudados por los Estados miembros "por cuenta de la Unión".

${ }^{63}$ Art. 2 de la Directiva 2010/24/UE del Consejo, de 16 de marzo de 2010, sobre la asistencia mutua en materia de cobro de los créditos correspondientes a determinados impuestos, derechos y otras medidas.

${ }^{64}$ El art. 2 de la derogada Directiva 2008/55/CE del Consejo, de 26 de mayo de 2008, sobre la asistencia mutua en materia de cobro de los créditos correspondientes a determinadas exacciones, derechos, impuestos y otras medidas, DOUE L 150 de 10 de junio de 2008 , p. 28 , que fue sustituida por la actual vigente, hacía una enumeración mucho más concreta. Así, se hablaba específicamente de derechos de importación y de derechos de exportación en sus apartados c) y d). Sin embargo, la actual Directiva 2010/24/UE se podría tildar de "comprensiva" (M. SANTOLAYa Blay, "La asistencia mutua en el ámbito de la recaudación: origen y evolución”, Carta Tributaria-Monografias, $\mathrm{n}^{\circ}$ 13, 2010, p. 5).

${ }^{65}$ A. Montero Domínguez, "La nueva Directiva Comunitaria de asistencia mutua en materia de recaudación: análisis del articulado de la norma positiva", Carta Tributaria-Monografias, $\mathrm{n}^{\circ}$ 14, 2010, pp. 27-28.

${ }^{66}$ J. F. García De Pablos, "La asistencia mutua en materia de cobro de créditos tributarios y derechos", Revista española de Derecho Financiero, $\mathrm{n}^{\mathrm{o}} 155,2012$, p. 3.

${ }^{67}$ A. Montero Domínguez, ob. cit., pp. 27-28.

${ }^{68}$ F. García De Pablos, ob. cit., p. 4.

${ }^{69}$ A. Montero Domínguez, ob. cit., p. 12. 
49. Nos interesa destacar, en particular, una herramienta importante en la lucha contra el fraude aduanero como es el cobro de créditos aduaneros por parte de otro Estado miembro, por parte del Estado requerido, manifestación prevista, igual que las dos anteriores que se acaban de poner de manifiesto, en la Directiva que se aborda. Para que este cobro se pueda llevar a término, se requiere de la existencia de una petición de cobro y de un instrumento uniforme que posibilite su ejecución en el Estado miembro requerido ${ }^{70}$.

50. La petición de cobro, como regla general, no puede tener como objeto un crédito o un instrumento que haya sido impugnado y que no haya resolución de tal controversia. Además, esta petición de cobro tiene un carácter subsidiario, generalmente, porque desde la Directiva se especifica el Estado requirente ha debido realizar previamente los procedimientos de cobro del crédito correspondiente establecidos en su Ordenamiento jurídico, permitiéndose en una serie de casos tasados, como que el deudor no disponga de bienes en el Estado requirente, pero los posea en el Estado requerido, o que la utilización de estos procedimientos de cobro en el Estado requirente conlleve consecuencias desproporcionadas ${ }^{71}$.

51. Por su parte, se requiere que tal petición vaya acompañada de un instrumento que posibilite la ejecución del crédito en el Estado requerido, que será la base exclusiva tanto de las medidas de cobro como de las posibles medidas cautelares ${ }^{72}$. Desde el punto de vista temporal, es muy positivo el hecho de que este instrumento no necesite de un reconocimiento por parte del Estado requerido, ya que abrevia los plazos evitando un nuevo paso administrativo. En cuanto a su contenido, deberá incluir la información del instrumento inicial que permite la ejecución y una descripción del crédito (como su naturaleza, importe y componentes) y los datos necesarios para la identificación del deudor y de la Oficina liquidadora y/o que pudiese dar información en relación al crédito o su impugnación ${ }^{73}$.

\section{Los programas Hércules III y Aduana 2020}

52. Cuando se habla del Programa Hércules III, instaurado por el Reglamento (UE) $n^{\circ} 250 / 2014$ del Parlamento Europeo y del Consejo, de 26 de febrero de 2014, por el que se establece un programa para promover actividades en el campo de la protección de los intereses financieros de la Unión Europea (programa «Hércules III»), y por el que se deroga la Decisión n ${ }^{\circ}$ 804/2004/CE -en adelante, Reglamento 250/2014-, y del Programa Aduana 2020, establecido por el Reglamento (UE) n 1294/2013 del Parlamento Europeo y del Consejo, de 11 de diciembre de 2013, por el que se establece un programa de acción para la aduana en la Unión Europea para el período 2014-2020 (Aduana 2020) y por el que se deroga la Decisión n ${ }^{\circ}$ 624/2007/CE -en adelante, Reglamento 1294/2013-, se está haciendo referencia a dos programas de la Unión Europea que servirán a la lucha contra el fraude aduanero de una forma directa, como en el caso del Programa Hércules III, o indirecta, como el caso del Programa Aduana 2020.

53. Estos programas europeos tienen precedentes ${ }^{74}$, por lo que estamos ante una continuidad de políticas que se han venido ya practicando y ejecutando. Tal continuidad viene justificada, en el caso del Programa Hércules III, por los resultados positivos obtenidos, es decir, por los avances de la lucha contra el fraude, la corrupción y cualesquiera otras actividades ilegales que afectan a los intereses de la Unión Europea, el Hércules III tiene como objetivo consolidar los resultados obtenidos ${ }^{75}$. Por lo respecta

\footnotetext{
${ }^{70}$ F. ViSMARA, ob. cit., pp. 84-85.

${ }^{71}$ A. Montero DomíngueZ, ob. cit., pp. 14-15.

${ }^{72}$ Estas medidas cautelares habrán de estar previstas para supuestos similares en los Ordenamientos jurídicos del Estado requirente y del Estado requerido, atendiendo al art. 16.1 de la Directiva 2010/24/UE del Consejo, de 16 de marzo de 2010, sobre la asistencia mutua en materia de cobro de los créditos correspondientes a determinados impuestos, derechos y otras medidas.

${ }^{73}$ J. F. García De Pablos, ob. cit., p. 5.

${ }^{74}$ En el caso del Programa Hércules III, existió un Programa Hércules y un Hércules II. Por su parte, el Programa Aduana 2020 tiene como precedentes los programas Aduana 2000, 2002, 2007 y 2013 (M. FABIO, ob. cit., pp. 768-770).

${ }^{75}$ Considerandos 3 y 6 del Reglamento 250/2014.
} 
al Programa Aduana 2020, también se afirma los avances que se han logrado en materia de cooperación aduanera con los programas anteriores al citado Programa, cuyas actividades se espera que consigan la realización de la "Estrategia Europa 2020 para un crecimiento inteligente, sostenible e integrador mediante el fortalecimiento del funcionamiento del mercado interior" y, además, con este Programa se han de proteger los intereses económicos y financieros de la Unión Europea ${ }^{76}$, los cuales se ven afectados por el fraude.

54. La diferencia entre que uno sirva directamente a tal fin y otro lo haga indirectamente radica en el objeto y los objetivos de los reglamentos comunitarios que los desarrollan: si bien se ha fijado como objeto de cada Reglamento el establecimiento del Programa pertinente, también han añadido una finalidad en los preceptos que abordan el objeto, siendo combatir el fraude en el caso del Programa Hércules $\mathrm{III}^{77}$, pero obviando la referencia al fraude en el caso del Programa Aduana 2020 ${ }^{78}$. Sin embargo, cuando se acude a los objetivos específicos, no sólo es el Programa Hércules III el que menciona, de nuevo, la lucha contra el fraude, sino también viene recogido como objetivo -pero no como objeto- en el Programa Aduana 202079.

55. Para distinguir el ámbito de aplicación de sendos programas europeos, se retiene necesario ver qué actividades son subvencionables por cada uno. Por una parte, el Programa Hércules III distingue tres categorías de actividades: a) el suministro de asistencia técnica especializada a aquellas autoridades competentes de los Estados miembros (mediante equipos de investigación conjunta y operaciones transfronterizas, intercambios de personal para determinados proyectos o prestando apoyo técnico y operativo a las fuerzas policiales y a las autoridades judiciales, entre otros); b) la organización de actividades de formación especializada, talleres en los que se forme al personal en materia de análisis del riesgo o conferencias; y c) cualesquiera otras acciones que sirvan para el cumplimiento del objeto o de los objetivos del Programa $^{80}$. Por otra parte, el Programa Aduana 2020 prevé estos tres tipos de acciones: a) acciones conjuntas (seminarios, talleres, grupos de proyecto o equipos de investigación, entre otras); b) refuerzo de las capacidades informáticas; y c) actividades de formación y desarrollo del personal en materia aduanera ${ }^{81}$.

56. Como se expuso anteriormente, el fraude es un atentado contra los intereses financieros de la Unión. Por ello, las medidas a las que se acaban de hacer referencia no van a ser las únicas que van a servir directa o indirectamente a la lucha contra el fraude. Ahora bien, es posible que las cantidades abonadas para la realización material de tales acciones se utilicen de forma distinta de la prevista en ambos Reglamentos, derivando en fraude, corrupción u otras ilegalidades, por lo que se establecen controles y la posibilidad de medidas preventivas en el caso de que se detecten tales irregularidades ${ }^{82}$. No deja de ser paradójico que aquellos fondos destinados para actividades contra el fraude puedan ser objeto de fraude por una utilización distinta, pero existe tal posibilidad y la Unión Europea ha de proteger sus intereses financieros.

\section{La necesaria cooperación en materia de infracciones y sanciones aduaneras}

57. Por último, una asignatura pendiente en la cooperación europea en la lucha contra el fraude aduanero sería las infracciones y sanciones aduaneras. Es necesario poner de relieve la Propuesta ${ }^{83} \mathrm{de}$

${ }^{76}$ M. FABIO, ob. cit., pp. 771-772.

77 Art. 1 del Reglamento 250/2014.

${ }^{78}$ El art. 1.1 del Reglamento 1294/2013 menciona que el Programa Aduana 2020 se instaura para apoyar el funcionamiento de la unión aduanera.

${ }^{79}$ Art. 4 del Reglamento 250/2014 y art. 5.2 del Reglamento 1294/2013, respectivamente.

${ }^{80}$ Art. 8 del Reglamento 250/2014.

${ }^{81}$ Art. 7 del Reglamento 1294/2013.

${ }^{82}$ En tal sentido, vid. M. FABIO, ob. cit., pp. 773-774, así como los arts. 12 del Reglamento 250/2014 y 13 del Reglamento $1294 / 2013$.

${ }^{83}$ Hasta ahora, esta Propuesta de Directiva del Parlamento Europeo y del Consejo ha pasado por la Comisión Europea, el 
Directiva del Parlamento Europeo y del Consejo sobre el marco jurídico de la Unión para las infracciones y sanciones aduaneras ${ }^{84}$.

58. Pues bien, la unión aduanera es una competencia exclusiva de la Unión Europea y, en pro del reconocimiento mutuo de resoluciones judiciales y de la cooperación policial y judicial en asuntos de Derecho Penal que tengan una incidencia transfronteriza, es una prioridad de la Unión la lucha contra el fraude en tanto en cuanto afecta a sus intereses financieros, debiendo actuar ésta y los Estados miembros adoptando las medidas que se consideren oportunas ${ }^{85}$.

59. En materia de sanciones, el art. 42 del Código Aduanero de la Unión ${ }^{86}$ establece que serán los Estados miembros los que preverán las sanciones ante las violaciones del Derecho Aduanero de la Unión, atendiendo siempre a los principios de efectividad, proporcionalidad y carácter disuasorio. Resulta extraño establecer mediante la figura del Reglamento comunitario que los Estados miembros establecerán sanciones, convirtiéndose en una obligación para éstos, pero no haya existido ninguna directriz desde la Unión que tratase de uniformarlas ${ }^{87}$. Tal es así, que es la misma Propuesta de Directiva que se mencionaba anteriormente parte de la idea de que las sanciones van a tener distinta naturaleza y gravedad en función del Ordenamiento jurídico del Estado miembro de que se trate, por lo que estaríamos ante diferencias sustanciales, cuestión difícil de entender tendiendo en cuenta que la aplicación de la normativa aduanera está armonizada ${ }^{88}$.

60. De los principios enunciados, especial relevancia tiene el principio de proporcionalidad, que forma parte del Derecho de la Unión Europea y que tiene una vinculación directa para los Estados miembros, según el Tribunal de Justicia de la Unión Europea ${ }^{89}$. Es más, ha afirmado este Tribunal que los Estados miembros ejercerán sus competencias al amparo de los principios generales del Derecho comunitario $\mathrm{y}$, en particular, en el principio de proporcionalidad ${ }^{90}$.

61. Volviendo a la Propuesta de Directiva y teniendo como premisa que no se realizará un análisis crítico profundo de la misma en tanto se trata, en la actualidad, de una Propuesta, nos interesaría, sin embargo, destacar una idea. El principal problema que existe a la hora de realizar una crítica a esta Propuesta es precisamente su naturaleza, es decir, que no es una Directiva que se haya aprobado y que forme parte del Derecho derivado de la Unión. En este sentido, subsisten todavía algunos elementos de la Propuesta inicial, pero, como decíamos, no podemos saber si quedará incorporada a la Directiva que finalmente se apruebe ${ }^{91}$. La idea que nos interesaba destacar es que esta Propuesta se fundamenta

Comité Económico y Social emitió un Dictamen y, por último, en primera lectura ha emitido dictámenes el Parlamento Europeo y se ha debatido en el Consejo (Fuente: EUR-Lex https://eur-lex.europa.eu/legal-content/ES/HIS/?uri=CELEX\%3A52013 PC0884\#2017-07-13_DIS_byCONSIL).

${ }^{84} 2013 / 0432$ (COD).

${ }^{85}$ Consideramos que la fundamentación de lo anterior, que debería incluirse en los considerandos de la Directiva que finalmente se apruebe en relación a la Propuesta de Directiva del Parlamento Europeo y del Consejo sobre el marco jurídico de la Unión para las infracciones y sanciones aduaneras, debería ser: la competencia exclusiva de la Unión en relación a la unión aduanera (art. 3 del TFUE); la cooperación aduanera (art. 33 del TFUE); el espacio de libertad, seguridad y justicia (arts. 67 a 76 del TFUE), en general, y la cooperación judicial en materia penal y la cooperación judicial (arts. 82 a 89), en particular; la aproximación de legislaciones (art. 114 del TFUE); y la lucha contra el fraude (art. 325 del TFUE); además del art. 42 del Reglamento (UE) n 952/2013 del Parlamento Europeo y del Consejo, de 9 de octubre de 2013, por el que se establece el código aduanero de la Unión, que aborda la cuestión de las sanciones aduaneras.

${ }^{86}$ Reglamento (UE) n 952/2013 del Parlamento Europeo y del Consejo, de 9 de octubre de 2013, por el que se establece el código aduanero de la Unión.

${ }^{87}$ M. FABIO, ob. cit., p. 785

${ }^{88}$ Contexto general del Contexto de la Propuesta de la Exposición de motivos de la Propuesta de Directiva del Parlamento Europeo y del Consejo sobre el marco jurídico de la Unión para las infracciones y sanciones aduaneras.

${ }^{89}$ F. VISMARA, ob. cit., p. 307.

${ }^{90}$ STJCE 26 de octubre de 1995, Siesse, 36/94, Rec. 1995, p. 3586.

${ }_{91}$ Un ejemplo de los cambios significativos es que, al principio, la Propuesta incluía una categoría de infracciones, las "infracciones aduaneras con responsabilidad objetiva", es decir, que el sujeto cometería la infracción al realizar la acción u omisión 
en el art. 33 del TFUE, que versa sobre la cooperación aduanera. El motivo de la fundamentación en este precepto comunitario no es otro que el acercamiento tanto de las infracciones como de las sanciones aduaneras requiere de una cooperación entre el conjunto de los Estados miembros. De hecho, tal aproximación legislativa entre Ordenamientos jurídicos de los Estados miembros en esta materia sería Derecho derivado de la Unión Europea, pudiendo ésta reforzar la cooperación aduanera ${ }^{92}$.

\section{Conclusiones}

62. Es común el empleo de la terminología de "fraude aduanero" en el Derecho español, aunque la doctrina no se ha ocupado demasiado de otorgarle contenido. Se puede definir el fraude aduanero, partiendo desde el Ordenamiento comunitario, como aquella irregularidad, ya sea una acción u omisión, causada intencionalmente en el ámbito de ingresos distintos de los procedentes de los recursos propios comunitarios del IVA, que afecta a los intereses financieros de la Unión al ingresar una menor cuantía su Hacienda. Dicho de otro modo, el fraude aduanero sería toda reducción o elusión del pago de los derechos de aduanas que fuere contraria a Derecho.

63. Conviene una revisión del Reglamento 515/97 y del Convenio Nápoles II con el fin de mejorar la calidad legislativa, sobre todo en relación a los preceptos que abordan el ámbito de aplicación de cada uno de ellos. No es una cuestión trivial porque ambos tratan mecanismos de asistencia mutua, con medidas muy similares, por lo que debe facilitarse la cooperación entre Administraciones de los Estados miembros y también entre éstas y la Comisión. Es imprescindible que tales acciones de asistencia mutua se fundamenten en textos jurídicos que garanticen seguridad jurídica por parte de quienes se beneficiarán de su aplicación.

64. La digitalización de las aduanas en la Unión Europea ha sido un avance significativo en la lucha contra el fraude aduanero, ya que ha permitido un mayor control en los procedimientos aduaneros $\mathrm{y}$, además, ha ahondado en el intercambio de información entre autoridades que investigan infracciones a la normativa aduanera con la puesta en funcionamiento del SIA, que contiene otra base más específica como es el FIDE. Un paso notorio fue que tanto la Europol como la Eurojust pudiesen acceder al SIA $\mathrm{y}$ al FIDE.

65. La asistencia mutua en materia de cobros de créditos aduaneros, establecida por la Directiva 2010/24/UE del Consejo, de 16 de marzo de 2010, sobre la asistencia mutua en materia de cobro de los créditos correspondientes a determinados impuestos, derechos y otras medidas, es muy positiva para la lucha contra el fraude aduanero y, por ende, para la Hacienda de la Unión Europea, ya que permite que los Estados miembros, que son los encargados de gestionar el procedimiento de recaudación de los derechos de aduanas, de titularidad de la Unión, puedan llevar a cabo el cobro de los créditos que surgen por la realización del hecho imponible de estos tributos. Cabe destacar también permite la asistencia mutua para el cobro de deudas de tributos de los Estados miembros. En fin, se puede afirmar que es un instrumento necesario para evitar el fraude aduanero y el fraude fiscal.

66. Han contribuido de forma significativa a la lucha contra el fraude aduanero la instauración de programas de cooperación, como el Programa Hércules III o el Programa Aduana 2020. Programas que, además, son la continuación de otros anteriores y, además, se ha decidido seguir con otras versiones

de la infracción sin tener en cuenta el elemento culposo. Distinguía entre estas infracciones, las cometidas por negligencia y las cometidas dolosamente. Pues bien, si la Propuesta de 2013 lo preveía así, la Posición del Parlamento Europeo aprobada en primera lectura el 5 de julio de 2017 eliminó tales distinciones, por lo que se reincorpora la necesidad de que exista el elemento culposo y dejó en un solo artículo el conjunto de acciones u omisiones que deberían estar castigadas en los Ordenamientos jurídicos de los Estados miembros (A. GARCíA Heredia, "Responsabilidad, avales y sanciones en las operaciones de comercio exterior: propuestas para una reforma de la LGT y del IVA a la importación”, Revista Española de Derecho Financiero, n 184, 2019, p. 9).

${ }_{92}$ F. Vismara, ob. cit., pp. 308 y 309. 
con el objeto de seguir combatiendo el fraude aduanero, con actividades tan necesarias como actividades de formación, seminarios o equipos de investigación.

67. Consideramos insuficiente la fundamentación normativa de los considerandos de la Propuesta de Directiva, ya que es vaga, y el legislador comunitario debería ser preciso al determinar jurídicamente el motivo por el que se decide aproximar legislaciones de los Estados miembros vía Directiva. Por otro lado, creemos que es necesaria la aprobación de la de Directiva del Parlamento Europeo y del Consejo sobre el marco jurídico de la Unión para las infracciones y sanciones aduaneras que vendría a uniformar las infracciones y sanciones en sede aduanera, lo que conllevaría una reducción del fraude aduanero, dado que la cooperación entre Administraciones aduaneras y entre Estados miembros y Comisión se llevaría a cabo sobre unas bases comunes, sobre un mínimo común denominador.

68. Uno de los fines últimos de la búsqueda de mecanismos de cooperación contra el fraude aduanero en la Unión Europea debe ser la justicia tributaria. Desde la óptica del Derecho Tributario español, sería más correcto hablar de principios materiales de justicia tributaria, los cuales encuentran un reflejo en el apartado 1 del art. 31 de nuestra Constitución. Sin embargo, aunque en el Derecho originario comunitario no existe una positivización de unos principios de justicia tributaria, sí pueden ser perfectamente reconducibles a través del reconocimiento en este Derecho primario de la Unión del derecho de propiedad, que sí esta contemplado expresamente ${ }^{93}$.

\footnotetext{
${ }^{93}$ Sobre esta cuestión, vid. C. M. López Espadafor, "Lagunas en el Derecho Tributario de la Unión Europea", Cuadernos de Derecho Transnacional, vol. 9, $\mathrm{n}^{\circ}$ 2, 2017, p. 380. La justicia tributaria es fundamental a la hora del desarrollo del Derecho Tributario de la Unión Europea, por lo que la delimitación de éstos se convierte en un tema crucial; en este sentido, vid. C. M. LóPEZ EsPaDAFor, "Tax justice issues in the European Union”, Cuadernos de Derecho Transnacional, vol. 11, n 2, 2019, pp. $232-234$.
} 